\title{
Erratum to: Demography and Life Histories of Sympatric Patas Monkeys, Erythrocebus patas, and Vervets, Cercopithecus aethiops, in Laikipia, Kenya
}

\author{
Lynne A. Isbell • Truman P. Young • \\ Karin Enstam Jaffe • Anne A. Carlson • \\ Rebecca L. Chancellor
}

Published online: 7 October 2010

(C) Springer Science+Business Media, LLC 2010

\section{Erratum to: Int J Primatol (2009) 30:103-124 DOI 10.1007/s10764-009-9332-7}

In the original Fig. 1, the callitrichids were inadvertently omitted, not just the strepsirrhines as stated in the text. We correct this with a revised figure that includes all primates for which we have data. Because the residuals are calculated from a new regression (additional data points), their absolute values shift slightly; nonetheless, the pattern remains the same: vervets lie very near the regression line of $r_{m}$ versus $\ln$ body size (residuals near zero), whereas patas monkeys have a very high $\mathrm{r}_{\mathrm{m}}$ for their body size. The point to the right of the patas monkeys represents ruffed lemurs, Varecia variegata.

The online version of the original article can be found at http://dx.doi.org/10.1007/s10764-009-9332-7.

L. A. Isbell $(\bowtie) \cdot K$. E. Jaffe $\cdot R$. L. Chancellor

Department of Anthropology, University of California, Davis, CA 95616, USA

e-mail: laisbell@ucdavis.edu

\section{T. P. Young}

Department of Plant Sciences, University of California, Davis, CA 95616, USA

\section{K. E. Jaffe}

Department of Anthropology, Sonoma State University, Rohnert Park, CA 94928, USA

\section{A. A. Carlson}

Department of Zoology, University of Wisconsin, Madison, WI 53706, USA

\section{A. A. Carlson}

Defenders of Wildlife, 109 S. 8th St., Bozeman, MT 59715, USA 
Fig. 1 Histogram of the residuals for the linear regression between body mass and maximum potential rate of increase, both log-transformed (data from Ross 1992). The 2 highlighted data points are for vervets and patas monkeys indicating that vervets lie precisely in the regression line, but patas monkeys have the greatest maximum potential population growth rate for their body size of any haplorhine primate.

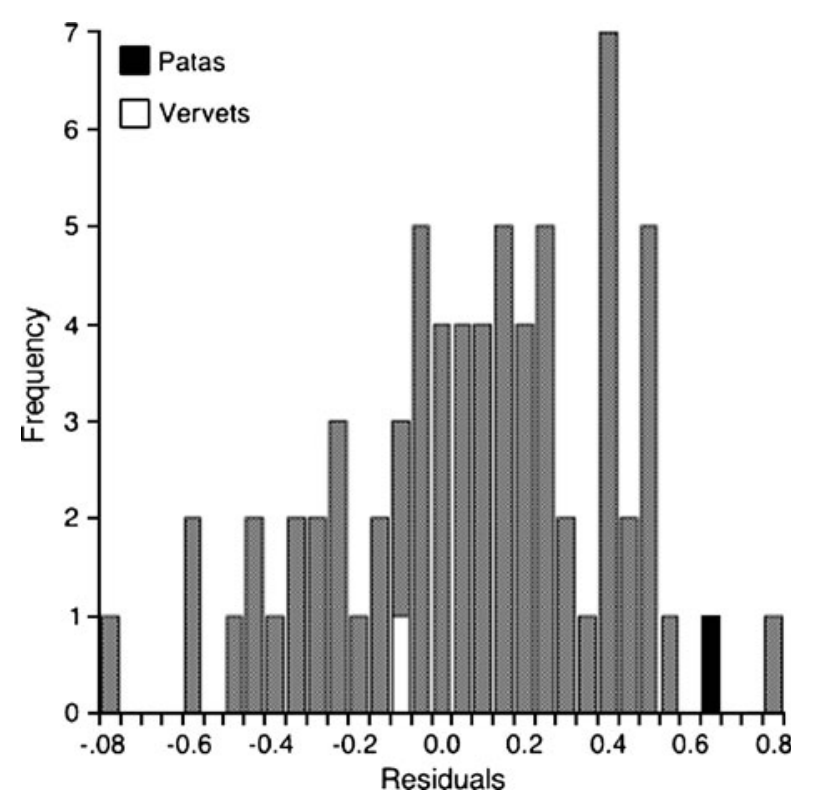

